ISSN: 2162-3104 Print/ ISSN: 2166-3750 Online

Volume 8, Issue 1 (2018), pp. 453-472

(C) Journal of International Students

http://jistudents.org/

doi: $10.5281 /$ zenodo. 1134338

\title{
"Home Away from Home"? How International Students Handle Difficult and Negative Experiences in American Higher Education
}

\author{
Lu (Wendy) Yan \\ Shaohua (Linda) Pei \\ Iowa State University, United States
}

\begin{abstract}
International students attending American universities often receive confusing messages: on one hand, for their contribution to the U.S. economy and fostering of domestic students' multicultural awareness; on the other, they are often targets of hostility and bias on and off campus. This qualitative phenomenological study examined 12 international students' perceptions of difficult and negative experiences in the context of American culture and a reputedly friendly Midwestern university. Four major themes emerged: (a) their on-campus experiences; (b) the off-campus experiences; (c) their reasons for unpleasant experiences, and (d) their suggestions for professors and peers to be more inclusive. Besides these students' struggles with administrators, faculty, and domestic students, their off-campus challenges sometimes dimmed their hopes for truly having a "home away from home."
\end{abstract}

Keywords: discrimination, international students, cultural struggles

Although international students are an asset to higher education in the
United States, both economically and culturally, they face unique challenges
in their adaptation to the culture and educational system, as the results of our
study illustrate. Each year, American colleges and universities enroll a
significant number of international students, which increased by $7.1 \%$ to 
more than a million $(1,043,839)$ in 2015-2016. These numbers are expected to increase in future years (International Institute of Education [IIE], 2015). Besides their economic impact, this influx of international students adds to the diversity of American campuses, and promotes and broadens domestic students' cultural awareness and experience of diversity (Luo \& JamiesonDrake, 2013; Ramos, Cassidy, Reicher, \& Haslam, 2016; Zhao, Kuh, \& Carini, 2005). According to the IIE (2007),

"U.S higher education is the country's fifth largest service sector export, as. . . [international] students bring money into the national economy and provide revenue to their host states for living expenses, including room/board, books and supplies, transportation, health insurance, support for accompanying family members, and other miscellaneous items."

However, in contrast to their domestic counterparts, international students who come to the U.S. with a certain level of confidence and academic preparation may struggle to live and study in this unfamiliar culture with its unfamiliar education system. Although international students are clearly not a homogeneous group by any means - in fact very diversestudies have shown that students from various cultures have similar challenges adjusting to American culture and education practices. Compared to their American peers, international students are more likely to become alienated, stressed out, or even depressed (Grey, 2002; Mori, 2000; Pedersen, 1991). Even many of their European peers who are predominantly White find it easier to fit into American society (Yeh \& Inose, 2003), while Latin American and Asian international students have higher levels of stress adapting to American culture (Lee, 2007; Wilton \& Constantine, 2003). Moreover, international students have difficulty adjusting to interactive, participatory and competitive American classroom methods (Ramsay, Barker, \& Jones, 1999; Tran, 2008; Zhao, Kuh, \& Carini, 2005).

Addressing these cultural and academic adaptation issues is mainly seen as the international students' own responsibility, and that they should "persist, overcome their discomfort, and integrate into the host society" (Lee \& Rice, 2007, p. 388). Host institutions thus are often regarded as being without fault in regard to these students' struggles (Lee \& Rice, 2007, p. 388). However, while being responsible for their own cultural adaptation or coping, international students can face exclusion, prejudice, questioning of their academic credibility, and discrimination (Lee \& Rice, 2007). For example, African female science students have reported negative interactions and lack of support by their White professors (Beoku-Betts, 
2004). Students not originally from Western or English-speaking countries (i.e., East Asians, Central and South Americans) have suffered hostility, discrimination, and harassment (Lee \& Rice, 2007; Leong \& Chou, 1996), causing them to devalue their own ethnic/racial group, justify the inequalities, and legitimize their status quo by believing that they deserve such a low status (Ramos, Cassidy, Reicher, \& Haslam, 2016).

Generally, international students have often received misleading and confusing messages: on one hand, they are heavily recruited, i.e., for their economic importance (Horta, 2009; Mazzarol, 1998); on the other hand, they may be targets of hostility from the host culture, i.e., facing discrimination and bias (Schmitt, Spears, \& Branscome, 2003; Yeh \& Inose, 2003). In our study, we aimed to understand the hostile side of this confusing message: the nature of international students' unfriendly experiences, especially when studying in what is considered a relatively friendly environment at a Midwestern university.

\section{LITERATURE REVIEW}

We based our qualitative study of a number of international students' adaptations to this American university on two theoretical approaches that provided context for their experiences of discrimination and bias.

\section{A Sense of Belonging}

"One component of connecting one's self [with] the fabric of surrounding people, places, and things is a sense of belonging" (Hagerty, Lynch-Sauer, Patusky, Bouwserna, \& Collier, 1992, p. 173), defined as a sense of (a) being valued, needed, and accepted, and (b) being a complement to an environment or a system (Anant, 1966; Hagerty et al., 1992). A lack of a sense of belonging may produce some negative effects and even pathological consequences (i.e., stress, depression, health problems, etc.) for a person (Hagerty et al., 1992). For example, when international students, often with very different cultural and ethnic backgrounds, struggle with discrimination and bias from their host American community, they can fail to have a sense of belonging to it. As a result, they may become stressed and depressed (Yeh \& Wang, 2000) and withdraw from the environment (Kim, 2012).

It is not easy, of course, to achieve a sense of belonging, especially when interacting with strangers or new acquaintances in a new place (Baumeister \& Leary, 1995), which is often the case for international 
students. As for most, "repeated interactions with the same person(s), and relatedness [with] frequent contacts" must be satisfactory to have met the need to belong (Baumeister \& Leary, 1995, p. 497). Furthermore, research has clearly established that lacking a sense of belonging is correlated with suffering discrimination and bias (AhnAllen, Suyemoto, \& Carter, 2006; Hurtado, Ruiz Alvarado, \& Guillermo-Wann, 2015; Jayaweera \& Choudhury, 2008). Exclusion from a community or society (i.e., discrimination, comments about differences, and subtle looks and stares that convey the impression 'you do not belong here') precludes or diminishes any sense of belonging to this community or society (AhnAllen et al., 2006, p. 683).

\section{The System Justification Theory}

The System Justification Theory (SJT; Jost \& Banaji, 1994; Jost, Banaji, \& Nosek, 2004; Jost, Glaser, Kruglanski, \& Sulloway, 2003) proposed that people become satisfied and motivated by defending and justifying the status quo, rationalizing stereotypes, and legitimizing inequality as natural and appropriate attitudes. People, including some from disadvantaged groups, may accept and provide explanations, "pseudo explanations" or even "placebo explanations" to not only feel better but also to ascribe legitimacy to out-group favoritism, i.e., a preference for other groups who have more power (Haines \& Jost, 2000; Jost et al., 2004; Kappen \& Branscombe, 2001). The SJT suggests that individuals who experience social exclusion may internalize and perpetuate social inequality and injustice, even taking blame for it themselves.

For example, according SJT motives, women may often believe that they deserve to be paid less than men (Hough \& Yoder, 2003); and people who are disadvantaged may believe that they deserve less because they are "lazy, unintelligent, poorly educated, or irresponsible . . losers" (Blasi \& Jost, 2006, p. 1,130). Without exhibiting SJT motives, instead of blaming themselves "people might challenge the system and reject it as unfair and exploitative ... [and believe that] it must be the fault of others or of the system itself" (Blasi \& Jost, 2006, p. 1130) when they suffer from inequalities and injustices.

Thus, we predicted that the international students in our study who have experienced discrimination and bias would exhibit the SJT motives, rationalizing their negative and hostile experiences and legitimizing this kind of oppression by favoring the "other" group - or those who are more powerful. 


\section{RESEARCH METHOD}

After receiving IRB approval, we undertook this qualitative phenomenological study at a large public research university in the Midwestern U.S., where people are known for their politeness and niceness (Atkins, 2008; Kuang, 2016) and their agreeableness and conscientiousness (Rentfrow, Gosling, \& Potter, 2008). In fall 2015, this campus had enrolled more than 4,000 international students from 110 countries and regions around the globe. In this presumed relatively friendly and diverse environment, our goal was to explore whether or not a number of international university students had experienced hostility on or off campus, and if there were differences between those experiences.

We sought an understanding of their experiences in order to suggest changes in policies and practices that could create a more inclusive and adaptable collegiate climate for these international students. We asked the following exploratory questions: In general, what were your on- and offcampus experiences, particularly regarding discrimination and harassment? If you had such experiences, how do you think you handled the situations? What suggestions do you have for the university, faculty and staff, and American students, respectively, to help create a better experience for international students?

\section{Data Collection}

Therefore, to understand the hostile side of international students' experiences at this particular institution and off-campus, we chose a phenomenological approach for our study. This approach centers on the lived experiences of the subjects (Van Menan \& Adams, 2010), emphasizes deeper and insightful descriptions and discoveries of everyday life (Osborne, 1994), and seeks "the truth" of a phenomenon and experience gained through numerous eyes and interpretations (Starks \& Trinidad, 2007). We wanted to hear the lived experiences of a sample of international students as they adapted to a new cultural and educational environment at this Midwestern university.

\section{Participants}

Following suggestions for choosing purposive samples for a phenomenology (Guest, Bunce, \& Johnson, 2006; Patton, 2002), we chose 12 international students, meaning they were neither U.S. citizens nor U.S. 
green card holders but were on F-1 visas only while studying in the United States These participants were from different countries/regions, had different majors and levels of education, and their years in the United States ranged from 1 to more than 10 . We recruited our first few participants through our personal contacts, which snowballed, providing us additional participants.

When choosing our sample size, we also considered what would be the data saturation point as suggested by Kuzel (1992). Thus, we interviewed 12 international students only until we reached data saturation, that is, when we were gaining no new information. Considering the importance of the transcription process for qualitative studies, we audiorecorded all the interviews with the participants' permission (McLellanLemal, MacQueen, \& Niedig, 2003).

\section{Interviews}

All the interviews were semi-structured, audio-recorded, and conducted one-on-one in quiet semi-private library rooms on campus. Each interview typically ranged from 45 to $60 \mathrm{~min}$. We hoped that such focused conversations in a private setting would provide us with in-depth knowledge on the topic (deMarrais, 2004). We assured the participants of complete anonymity.

At the beginning of each interview, we followed Saldana's (2011) suggestions for demystifying the interview process in order to create a more equitable relationship with those we interviewed. Therefore, we explained to each participant the purpose of the study and how the interview mechanics worked, went over the informed consent form, and told them that our iPod was being used as an audio recorder but could be turned off at any time if they did not want something recorded.

After each participant signed the consent form, we followed our scheduled interview protocol and probes, which included 10 questions based on previous literature about individuals' experiences of discrimination and bias. But oftentimes we were led by the participants' voluntary conversations and responses themselves. Using a discourse of complex interpersonal conversation between the participants and ourselves as two researchers (Ahrens \& Dent, 1998; Qu \& Dumay, 2011), we tried to learn about their challenges as international students in a different culture and educational setting from their home country. 


\section{Data Analysis}

For our data analysis, we applied Hycner's (1985) guidelines, emphasizing his principle of remaining true to the phenomenon, that is, we "used the matrices of that person's [the participants"] world-view in order to understand the meaning of what [they were] saying" (Hycner, 1985, p. 281). This analysis process had four steps. First, we listened to each audio interview several times and then transcribed all the recordings. Second, once we were assured of the accuracy of our transcriptions, we extracted relevant meanings and grouped them into clusters of themes. Third, we grouped the themes into categories that were "common to most or all of the interviews as well as the individual variations" (Hycner, 1999, p. 154). Finally, we examined the results of our data and triangulated our analysis by checking back with our participants and sample validation- "people eligible to participate, but who did not" (Larkin \& Thompson, 2012, p. 112). We also each kept a journal of notes and impressions for a clear audit trail.

\section{RESULTS}

Four themes emerged from our data analysis, all related to the 12 international students' perceptions of their American university experiences: (a) on-campus experiences, (b) off-campus experiences, (c) willingness to find reasons/excuses to explain their unpleasant experiences, and (d) suggestions for faculty and domestic students to help make their American experience better. In the succeeding sections, we deliberately excluded the participants' country/region of origin, or majors. We wanted to protect their anonymity, and more importantly to only highlight their discriminatory experiences without suggesting any presumptive stereotypes. The following themes were derived from the interview data.

\section{On Campus: "Please don't be too mean to us."}

The literature has commonly reported that English as a Second Language (ESL) students' academic writing in English is poor. Moreover, international students' struggles to write an assignment in English may take double or even triple the time of non-international students. Despite these second-language students' efforts, their professors may still fail them for their substandard English.

One participant in her interview said "it is unfair" five times to express her frustration with how an instructor failed almost all the 
international students in her statistics class because he said, "I [the instructor] don't understand your English writing." This student added,

"It [was] a statistics class and so we focused more on calculating and running the data. He did not even give us a second chance to revise our writing. I got a zero on a big paper because he said my English writing is confusing. It was a 15-page paper. You know, I had spent a lot time and energy on that paper and had actually done well in my previous assignments."

Later, this participant said she received a warning from her department for failing this class and had to meet with her department dean to discuss the potential consequences. On an F-1 visa, all international students must maintain a good GPA status, because if it drops too low, they may become academically disqualified and have to return to their home country. While this student agreed that she needed to work harder next time, she had also "learned" to always check with other students before enrolling in any class, to see if the professor had a reputation for not liking international students. "Professors, please be patient and not too mean to us," she added when asked to offer suggestions for improving the international students' situation.

While discussing these students' interactions with professors-after a pause of about $10 \mathrm{~s}$ and a few statements such as "I don't want to get into any trouble," one participant reflected on how hurt and unfairly treated she felt after being asked by her instructor to drop a class:

"I registered for a class very early on but was told to drop it before the class started. The instructor emailed me that there were some other people who needed that course 'more' than I did. How could she say that? I needed that class too and that's why I registered it early. . I checked and the class was not just open for certain students [e.g. graduate students or students from that department]."

This student did drop the class eventually but questioned whether all students had equal access to it. In addition to some unpleasant interactions with instructors, another participant talked about classmates who demonstrated "lukewarm" attitudes toward them:

"They don't care what I say and they are just not interested. When I talk about my culture, they are not rude but very indifferent and uninterested (not even having eye contact with me), and they don't even bother to hide their indifference." 
She expressed feeling "powerless and invisible" when interacting with her domestic classmates. When asked for suggestions, she recommended that her international peers try to really "prove that they know their stuff" to the domestic students. Otherwise, "they may not accept you." Three other participants also advised their fellow international students to "prove yourself."

Even when these students were driven to do well in their work, they sometimes received a "cold shoulder" from some of their instructors and classmates, as their efforts were often not seen as valuable in class. Moreover, a stereotype of East Asian students as being quiet may have been reinforced. Domestic students likely did not get the same message as the international students to "work harder next time" or "avoid taking this instructor's class in the future" when they got an unfair failing grade or were asked to drop a class. International students are often perceived as poor English speakers and writers and may therefore be more likely to get a failing grade on a paper or be ignored in group discussions.

\section{Off-Campus: "You are welcome to study here but we are not equal."}

Oftentimes international students' off-campus experiences are not sufficiently discussed, but can also represent a major problem with respect to their successful participation in the American cultural setting.

International students may experience impersonal and direct aggression more often off campus than on (Poyrazli \& Grahame, 2007), although it remains unclear whether international students are viewed as American minorities or foreigners when they are unfairly treated. However, it is clear that they experience more shocking harassment when shopping, eating at restaurants, being at airports, or simply walking in public off campus. The following incident illustrates one participant's treatment off campus. She reported being viewed as a thief when shopping:

"I bought a hat for my kid from a retail chain store and when we were shopping in the same chain store but in a different location, she was wearing the hat. The store clerk stopped us and asked me to pay if my kid's hat was from this store. I told her I bought it from a different store but she didn't believe me until I showed her my receipt. I was relieved that I still had the receipt on me."

Other participants described being "ignored," "followed around," "stared at," and one said of a sales associate, "They pretended that they didn't understand my English even though I had just asked how much it is." 
Another participant laughed and suggested that she should wear something expensive when shopping next time. She expressed the irony that her money may be in the form of U.S. dollars but still be seen as less valuable.

In addition to such unpleasant shopping experiences, being in an airport or on an airplane are other places where international students might experience discriminatory treatment, as one participant recalled:

"A woman was sitting in my [window] seat on a flight, but she just ignored me when I said that was my seat. I showed her my ticket. So I went to a flight steward asking for help. Maybe because my English was not fluent then, do you know what the steward asked me? She said, 'Well, don't you want to sit somewhere else?!'”

This student did give up her seat and sat 'somewhere else' on the plane, but shared how scared and ashamed she felt during this incident. Two participants shared similar experiences of discrimination when going through airport security and being required to take much longer than "normal" people. These two women were wearing hijabs (head scarves), and one said, "It feels embarrassing but it is okay. I understand."

Another participant reported being yelled at when she was walking off campus with her daughter one day:

"When my daughter [5 years old] and I were walking on a sidewalk one time, a driver started yelling at us, suddenly. Made me uncomfortable. I don't think they would do this to anybody. I think they just find a target to do this. Maybe they [were doing it] just for fun, maybe because you are a foreigner or your look differently, but it's very uncomfortable and [scary], especially at night."

Yet another shared his view of unequal treatment by domestic students:

"You get the sense [feeling] that they [domestic students] are like, 'in a way we take you as one of us but we are not equal.' They treat me as a guest and they are kind of welcoming me but that doesn't necessarily mean they treat me equal. So you kind of get the feeling that 'yes, I'm glad that you came here and study, but we are not equal'."

A common struggle among the participants was related to the fact that, while different offices on campus may be immediately available for them to report negative incidents, they knew of no place to seek help if unpleasant things happen to them off campus. Many were not aware of their 
rights or whom to turn to for support. One participant used the word "gap" to illustrate his feeling of isolation with respect to this matter.

\section{Reasons for Unpleasant Experiences: "Everything is my fault."}

All the participants first blamed themselves when they had unpleasant experiences. Most chose to ignore unpleasant interactions and actively searched for reasons to make themselves feel better. Often they felt they must be content with what they got, thinking they have no other choice:

"It is my fault. My English is not good enough or my culture $i$. different." [She failed a statistics class because of her unacceptabl, English writing.]

"Maybe they are [yelling at us] just for fun." [She and her daughte. were yelled at by a motorist while they were walking on a sidewalk.]

"I am new here and so they may want to take advantage of me. understand. I understand." [He was asked to pay extra money anc clean an off-campus apartment before moving in.]

"We look different and we are foreigners." [She was treated as c thief in front of her daughter in a retail chain store.]

"We should work harder so that they will know we are nice people. [They were wearing hijabs.]

"They [domestic students] are in a bad mood. Or they had a bac day." [She was ignored when she was talking about her culture ir group projects.]

"It is in the past. It is fine." [She had to give up her assigned seat or a flight.]

"I don't want to get into any troubles because I am on an F-

1 visa and have no leverage to negotiate with them [instructors]. I had to keep quiet." [She was asked by the instructor to drop a class.]

One participant asserted "I understand" quite a few times when he was describing how he interacted with both his lukewarm classmates and his apartment landlord. The participant who was yelled at for no apparent reason while walking on a sidewalk also speculated "because maybe we look different." Two participants explicitly expressed concern that they might damage their F-1 visa status if they complained. 


\section{Suggestions for Better Experiences: "Mutual understandings."}

International students usually travel far away from their family and friends in order to pursue a better education in the U.S. It was all the participants' hope to also have a pleasant study-abroad experience while they furthered their education at this university. Therefore, most of the study participants suggested the need to move toward "a mutual understanding" between international and domestic students, as well as between international students and faculty and staff. One participant encouraged domestic students to "take adapting/adjusting seminars on different cultures. International students are strongly recommended to learn this [American] culture but learning and understanding should be reciprocal." Another participant shared her view that "some domestic students are not ready for diversity, saying it is beneficial for them to learn [about] our culture too. In addition, international students should be more positive and show them that we are nice people." Other participants specifically suggested that domestic students try to understand the importance of particular holidays to some cultures. As one put it: "They [domestic students and citizens] are in a transparent bubble that's made of very strong material. You can see each other, but when you try to get into their bubble, you get hurt." Some participants even recalled that, as members of the majority in their home countries, they had not known how minorities felt, but that the experience of being an international student [and sometimes a minority] in the U.S. provided them with a new perspective. Another participant who has been in the U.S. longer than 10 years apparently still felt alienated by some Americans:

"This is like my second home country. I love it, so I get hurt when so many people are cold, hostile and have a superior mindset when they interact with us [international students]. I just wish they would truly accept our presence and appreciate our culture, instead of mimicking and laughing at our language. The world is getting more global. It should be good for them if they knew more than one culture, isn't it?"

Moreover, some participants hoped that university professors and staff could be more patient with international students, especially while they are overcoming homesickness, adapting to their new culture, and trying to do well in their studies at the same time. One participant shared how he interacted with a staff member at the international students office on campus: "Every time I talk to her, I feel I was ignored. I do not feel I am 
welcomed. It upsets my willingness to visit the office. I may get the answer I am looking for from her, but I am just not happy." Another participant wished her professors would have acknowledged the presence of international students in the class: "It would be better if my professors could make it clear on the syllabus, like to promote mutual cultural understanding and respect."

\section{DISCUSSION AND CONCLUSIONS}

The primary goal of this research was to advance our understanding of certain negative and unpleasant experiences that international students have had in a relatively diverse and friendly Midwestern university, both on and off campus. The findings of this study are particularly illuminating regarding those experiences and how these international students interpreted and gave meaning to them. Following the principles of a phenomenological methodology, as researchers we tried to allow the participants to speak "the truth" of their experiences and make their own interpretations (Starks \& Trinidad, 2007). They informed our ontological understanding of their plight as international students, providing a clear understanding of their struggles and mental anguish as a result of the treatment they received on and around this campus.

The participants in this study were searching for a sense of belonging in their new community and culture at some point in their education, and all showed a strong motivation toward such, according to their comments and observations. However, rather than criticize people in their host culture, some accepted responsibility for their treatment, believing that they needed to "be more positive to show them [domestic students and citizens] that we are nice people" and to "prove" their credibility so that domestic students would accept them, e.g., by working with them on group class projects. However, others who had experienced more rejection and exclusion preferred making friends with other international students rather than domestic students. As one participant explained, with resignation: "It is not easy to maintain friendships with domestic friends, so I now only make friends with internationals to save the fuss." Two other participants reacted similarly about recognizing their domestic classmates (i.e., group members) as friends, saying "they are not as close as [our] international friends." When international students feel unvalued, unaccepted, and ill-fitted to their new community (Hagerty et al., 1996), they alternatively will increase their identification with their home country, or with non-U.S. citizens in the 
category of international students, for they are more likely to share in the experience of being treated as an outsider or foreigner (Schmitt et al., 2002).

These students' relationships with individuals in their host culture and fellow international students is continuously changing, as suggested by their comments and insights. They range from experiencing outright discrimination and bias by individuals in the university and local community to some sense of belonging to their new cultural and academic community in this Midwestern setting at times. More comfortably, however, they often feel more accepted and a sense of belonging with individuals or groups from their home country and/or similar ethnic groups. The latter relationships are generally more satisfying and less stressful, especially when some see others' ability to meet them half way or be fair to them as international students as failures or short falls. In other words, they may take the path of least resistance, even though they wish people in their host culture, both on and off campus, to be more open to their culture. And in some cases, the international students' accept their professors' mistreatment, not wanting to jeopardize their academic standing necessary to retain their visa. The following are examples.

Besides wanting to belong in their new setting, the participants in our study either blamed themselves or the situation itself, rather than their American hosts, or tried to rationalize and defend their attitudes toward their negative experiences. Of all the reported discriminatory incidents among our 12 participants, seven completely and three partially blamed themselves or the situation itself for these reasons: (a) having imperfect writing skills and pronunciations in English to express themselves better; (b) not trying hard enough in a class in which the instructor seemed to be biased against international students, or to prove that they are capable of doing group work/homework; (c) looking different or wearing something different (e.g., a hijab) than their American peers; and (d) simply being seen as "foreigners" or "outsiders" as one participant stressed eight times in her interview. The other two participants neither blamed themselves nor the situation for being discriminated against, although they said they kept quiet after the incidents for fear of losing their F-1 visa status. One participant stated that "[her hecklers] may be young and looking for fun" to explain why she thought it was acceptable to be yelled at while walking with her daughter in public. Another emphatically stated, "I understand" regarding a few times some domestic students had asked him how many times he eats rice per day, and when they had treated him lukewarm in class, because he may have thought this was normal behavior toward a new "foreign" student. The participant who experienced the unpleasant incident on her airline flight 
shared that she felt ashamed and embarrassed at having to be moved by the flight attendant, and being made to surrender her seat to another passenger for no reason. Other participants frequently guessed, saying, "Maybe they are having a bad day" or "Maybe they treat everybody like that" or "Maybe my pronunciation is bad," although the latter had only asked for the price of an item in a store. Similar to other disadvantaged persons according to the System Justification Theory (Jost \& Banaji, 1994; Jost et al., 2003; 2004), the participants in this study blamed themselves first and found pseudo and placebo explanations for their unpleasant experiences. Instead of challenging and questioning their discriminatory treatment, they attributed the attitudes of domestic students and other U.S. citizens to their favoritism for American students, perhaps further perpetuating prejudices and biases towards international students.

We also think that it was a common phenomenon for the participants to feel powerless, helpless, and even fearful when they tried to integrate with their host culture. Half of the 12 participants used the word "being ignored" more than four times during their interview to describe their interactions with host Americans. Although other participants did not use the word "ignored," they described similar situations as being uncomfortable and awkward. For example, one participant cited feeling "helpless" when her classmates ignored and excluded her during assigned group work. Other participants would deliberately avoid responding to or questioning the people who treated them differently, fearing retaliation, especially when being so far away from their support system of family and friends.

After we reviewed the findings of our study in regard to these international students' experiences, we felt that perhaps higher education administrators, faculty, and even domestic students, if made aware of their own attitudes and actions, might realize what they have failed to do to help make these international newcomers feel that this Midwestern campus is truly their "home away from home."

\section{Limitations}

There were a few limitations to this study. First, there was a common distrust between a few of the participants and ourselves as the two researchers at the beginning of our interviews, as we felt their reluctance to share their discriminatory on-campus experiences. These participants paused a lot longer than the other interviewees before answering questions, and chose their words very carefully. They described their interactions with professors and classmates as cautiously and neutrally as possible until we 
asked similar questions, after which they gave different responses later in our interviews. However, we also felt that after we restated the purpose of the study, they were more open and truthful about their experiences and feelings. We realized that, in our roles as the researchers who are Asianand international students (graduate assistants) ourselves, it was a relatively easy to build rapport with the participants, some of whom were Asian.

Second, since all of the interviews were conducted in English, some of the participants struggled somewhat with their answers because of their limited English. To allow the participants to more accurately describe their experiences and express their feelings, we encouraged them to use an online dictionary and the Google search engine when they needed to look for appropriate English words. We both concluded that if the interviews had been conducted in the participants' native language, their responses would have been more powerful and insightful. However, we did bracket our transcriptions and analyses with member check-ins and sample validations to make sure their responses were accurately reported and analyzed. We used follow-up interviews with all the participants to do a member check.

\section{IMPLICATIONS}

Based on our findings, we suggest two interventions that could foster social inclusion for international students in American college settings. First, similar to what our participants mentioned, we suggest having an office or a program on campus to help international students process and cope with social interaction problems they experience both on and off campus, and if possible, direct them to the right offices on campus for help (e.g., the student counseling office, equal opportunity office). For example, one participant had to pay extra money before he moved into an off-campus apartment for no reason. A college or university could have an office or housing location service to help international students know where and how to find credible landlords, instead of letting students fend for themselves and "live and learn" unnecessarily. Different from the usual international students office which often mainly handles students' paperwork, forms, and other legal work, this office or program could bridge the gap between international students' need for a better experience and their challenges on and off campus. Second, because mutual understanding between domestic and international students is crucial for the social inclusion of the latter, we suggest a mandatory seminar for newly enrolled international students to understand American culture as well as mandatory cultural seminars for domestic students in order to know and understand various cultures better. 
Unlike regular orientation programs that usually last a few days, the seminar could be a full semester to foster both international and domestic students' mutual understanding and enhance their communication.

\section{REFERENCES}

AhnAllen, J. M., Suyemoto, K. L., \& Carter, A. S. (2006). Relationship between physical appearance, sense of belonging and exclusion, and racial/ethnic self-identification among multiracial Japanese European Americans. Cultural Diversity and Ethnic Minority Psychology, 12(4), 673-686. doi: 10.1037/1099-9809.12.4.673

Ahrens, T., \& Dent, J. F. (1998). Accounting and organizations: Realizing the richness of field research. Journal of Management Accounting Research, $10,1-39$.

Anant, S. S. (1966). The need to belong. Canada's Mental Health, 14, 21-27.

Atkins, A. (2008). Creating Minnesota: A history from the inside out. St. Paul: Minnesota Historical Society Press.

Baumeister, R. F., \& Leary, M. R. (1995). The need to belong: Desire for interpersonal attachments as a fundamental human motivation. Psychological Bulletin, 117(3), 497-529.

Beoku-Betts, J. A. (2004). African women pursuing graduate studies in the sciences: Racism, gender bias, and third world marginality. NWSA Journal, 16(1), 116-135.

Blasi, G., \& Jost, J. T. (2006). System justification theory and research: Implications for law, legal advocacy, and social justice. California Law Review, 94(4), 1119-1168.

deMarrais, B. K. (2004). Qualitative interview studies: Learning through experience. In K. B. de Marrais \& S. D. Lapan (Eds.), Foundations for research: Methods of inquiry in education and the social sciences (pp. 5168). Mahwah, NJ: Lawrence Erlbaum.

Grey, M. (2002). Drawing with difference: Challenges faced by international students in an undergraduate business degree. Teaching in Higher Education, 7(2), 153-166.

Guest, G., Bunce, A., \& Johnson, L. (2006). How many interviews are enough? An experiment with data saturation and variability. Field Methods, 18(1), 5982.

Hagerty, B. M. K., Lynch-Sauer, J., Patusky, K. L., Bouwserna, M., \& Collier, P. (1992). Sense of belonging: A vital mental health concept. Archives of Psychiatric Nursing, 6 (3), 172-177. doi: 10.1016/0883-9417(92)90028-H

Haines, E. L., \& Jost, J. T. (2000). Placating the powerless: Effects of legitimate and illegitimate explanation on affect, memory, and stereotyping. Social Justice Research, 13(3), 219-236. 
Horta, H. (2009). Global and national prominent universities: Internationalization, competitiveness and the role of the State. Higher Education, 58(3), 387405.

Hough, M., \& Yoder, J. D. (2003). The role of status in producing depressed entitlement in women's and men's pay allocations. Psychology of Women Quarterly, 27(4), 330-337. doi: 10.1111/1471-6402.00113.

Hurtado, S., Ruiz Alvarado, A., \& Guillermo-Wann, C. (2015). Creating inclusive environments: The mediating effect of faculty and staff validation on the relationship of discrimination/bias to students' sense of belonging, The Journal of the National Conference on Race and Ethnicity in American Higher Education, 1(1), 60-81.

Hycner, R. H. (1985). Some guidelines for the phenomenological analysis of interview data. Human Studies, 8(3), 279-303.

Hycner, R. H. (1999). Some guidelines for the phenomenological analysis of interview data. In A. Bryman \& R. G. Burguess (Eds.), Qualitative research (pp. 143-164). London: Sage.

International Institute of Education (2007). International student enrollment in U.S. rebounds. Retrieved Jun. 22nd from http://www.iie.org/en/Who-We-Are/ News-and-Events/Press-Center/Press-Releases/2007/2007-11-12International-Student-Enrollment-in-US-Rebounds\#.V2rEU_krLRY

International Institute of Education (2017). International students. Open Doors Data. Retrieved from http://www.iie.org/

Jayaweera, H., \& Choudhury, T. (Mar. 2008). Immigration, faith and cohesion. York Joseph Rowntree Foundation. Retrieved from http://www.compas.ox.ac. uk/media/FP-2008-011-Muslims_Cohesion2.pdf

Jost, J. T., \& Banaji, M. R. (1994). The role of stereotyping in system-justification and the production of false consciousness. British Journal of Social Psychology, 33(1), 1-27.

Jost, J. T., Banaji, M. R., \& Nosek, B. A. (2004). A decade of system justification theory: Accumulated evidence of conscious and unconscious bolstering of the status quo. Political Psychology, 25(6), 881-919.

Jost, J. T., Glaser, J., Kruglanski, A. W., \& Sulloway, F. J. (2003). Political conservatism as motivated social cognition. Psychological Bulletin, 129(3), 339-375. Retrieved from http://faculty.virginia.edu/haidtlab/jost.glaser. political-conservatism-as-motivated-social-cog.pdf

Kappen, D. M., \& Branscombe, N. R. (2001). The effects of reasons given for ineligibility on perceived gender discrimination and feelings of injustice. British Journal of Social Psychology, 40(2), 295-313.

Kim, E. (2012). An alternative theoretical model: Examining psychological identity development of international students in the United States. College Student Journal, 46(1), 99-113.

Kuang, Y. (2016). The investigation of Minnesota Nice in terms of trust, communication style and personality. Retrieved from http://conservancy.umn.edu/bitstream/handle/11299/ 
Kuzel, A. J. (1992). Sampling in qualitative inquiry. In B. F. Crabtree \& W. L. Miller (Eds.), Doing qualitative research: Research methods for primary care, Vol. 3 (pp. 31-44). Thousand Oaks, CA: Sage.

Larkin, M., \& Thompson, A. R. (2012). Interpretative phenomenological analysis in mental health and psychotherapy research. Qualitative research methods in mental health and psychotherapy: A guide for students and practitioners (pp. 99-116). New York: Wiley.

Lee, J. J. (2007). Neo-racism toward international students: A critical need for change. About Campus, 11(6), 28-30. doi: 10.1002/abc.194.

Lee, J. J., \& Rice, C. (2007). Welcome to America? International student perceptions of discrimination. Higher Education, 53(3), 381-409.

Leong, F. T. L., \& Chou, E. L. (1996). Counseling international students. In P. B. Pedersen (Ed.), Counseling across cultures (pp. 210-242). Thousand Oaks, CA: Sage.

Luo, J., \& Jamieson-Drake, D. (2013). Examining the educational benefits of interacting with international students. Journal of International Students, 3(2), 85-101.

McLellan-Lemal, E., MacQueen, K. M., \& Niedig, J. (2003). Beyond the qualitative interview: Data preparation and transcription. Field Methods, 15(1), 63-84.

Mazzarol, T. (1998). Critical success factors for international education marketing. International Journal of Educational Management, 12(4), 163-175.

Mori, S. C. (2000). Addressing the mental health concerns of international students. Journal of Counseling \& Development, 78(2), 137-144.

Osborne, J. W. (1994). Some similarities and differences among phenomenological and other methods of psychological qualitative research. Canadian Psychology/ Psychologie Canadienne, 35(2), 167.

Patton, M. Q. (2002). Qualitative research \& evaluation methods (3rd ed.). Thousand Oaks, CA: Sage.

Pedersen, P. B. (1991). Counseling international students. The Counseling Psychologist, 19(1), 10-58.

Poyrazli, S., \& Grahame, K. (2007). Barriers to adjustment: Needs of international students within a semi-urban campus community. Journal of Instructional Psychology, 34(1), 28-45.

Qu, S. Q., \& Dumay, J. (2011). The qualitative research interview. Qualitative Research in Accounting \& Management, 8(3), 238-264.

Ramos, M. R., Cassidy, C., Reicher, S., \& Haslam, S. A. (2016). A longitudinal study of the effects of discrimination on the acculturation strategies of international students. Journal of Cross-Cultural Psychology, 47(3), 401420.

Ramsay, S., Barker, M., \& Jones, E. (1999). Academic adjustment and learning processes: A comparison of international and local students in first-year university. Higher Education Research \& Development, 18(1), 129-144. 
Rentfrow, P. J., Gosling, S. D., \& Potter, J. (2008). A theory of the emergence, persistence, and expression of geographic variation in psychological characteristics. Perspectives on Psychological Science, 3(5), 339-369.

Saldaña, J. (2011). Fundamentals of qualitative research. New York: OUP.

Schmitt, M. T., Spears, R., \& Branscombe, N. R. (2003). Constructing a minority group identity out of shared rejection: The case of international students. European Journal of Social Psychology, 33(1), 1-12.

Starks, H., \& Trinidad, S. B. (2007). Choose your method: A comparison of phenomenology, discourse analysis, and grounded theory. Qualitative Health Research, 17(10), 1372-1380.

Tran, T. L. (2008). Unpacking academic practices: International students in management and education disciplines in Australian higher education. Higher Education Research and Development, 27(3), 245-256.

Van Manen, M., \& Adams, C. A. (2010). Phenomenology. International Encyclopedia of Education, 6, 449-455.

Wilton, L., \& Constantine, M. G. (2003). Length of residence, cultural adjustment difficulties, and psychological distress symptoms in Asian and Latin American international college students. Journal of College Counseling, 6, 177-186. doi: 10.1002/j.2161-1882.2003.tb00238.x

Yeh, C. J., \& Inose, M. (2003). International students' reported English fluency, social support satisfaction, and social connectedness as predictors of acculturative stress. Counseling Psychology Quarterly, 16(1), 15-28.

Yeh, C. J., \& Wang, Y. W. (2000). Asian American coping attitudes, sources, and practices: Implications for indigenous counseling strategies. Journal of College Student Development, 41(1), 94-103.

Zhao, C., Kuh, G., \& Carini, R. (2005). A comparison of international students and American student engagement in effective educational practices. Journal of Higher Education, 76 (2), 209-231.

LU (WENDY) YAN is a $\mathrm{PhD}$ candidate from School of Education, Iowa State University. Her research interests include student development and learning, international students, equality and inclusion. Email: lyan@iastate.edu

SHAOHUA (LINDA) PEI is a PhD candidate in the Higher Education program at Iowa State University. Her research interests include struggles and success of international students, internationalization of higher education, micro-aggression experience of Asian students, second language acquisition, and intercultural communication. Email: lindapei@iastate.edu 